\title{
Socialização na escola: transições, aprendizagem e amizade na visão das crianças $^{*}$
}

\section{Socialization at school: transitions, learning and friendship from children's point of view}

\author{
Fernanda Müller**
}

\begin{abstract}
RESUMO
O trabalho apresenta uma pesquisa etnográfica conduzida na cidade de Porto Alegre, onde se buscou entender os processos de socialização escolar a partir dos depoimentos de oito crianças. O artigo explora três temas, sendo o primeiro a transição de série que implica dificuldades, prazeres e medos. O segundo se refere à idéia de "ter futuro" como conseqüência das aprendizagens na escola, assim apresentada explicitamente pelas crianças mais pobres. Por último, o contexto do recreio é focalizado para mostrar a complexidade das relações de amizade entre pares.
\end{abstract}

Palavras-chave: crianças; escola; socialização.

\begin{abstract}
This paper presents an ethnographical study carried out in Porto Alegre/Brazil, and its main objective is to provide greater understanding of socialization processes at school from eight children's points of view. The work explores three issues, and the first one is related to transition of school years, what means difficulties, pleasures and fears. The second one is the idea of 'having future' as the consequence of learning at school, and it was presented specially by those poorer children. The last one is the break time which is focused in order to show the complexity of friendships among peers.
\end{abstract}

Keywords: children; school; socialization.

* Agradeço à Capes pelo apoio financeiro.

** Doutora em Educação, Professora da Universidade Federal de São Paulo. fernanda. mueller@gmail.com 


\section{Introdução}

Entre os anos de 2004 e 2006, conduzi uma pesquisa etnográfica em Porto Alegre, tendo como objetivo central analisar o entendimento de nove meninos e meninas, de quatro a doze anos, sobre a cidade em que habitavam. Para isso, construí uma abordagem metodológica que consistia na realização de fotografias pelas crianças, seguida de "conversações" (MAYALL, 2001), de forma a captar como as crianças escolhiam, significavam e entendiam os espaços-lugares ${ }^{1}$ mais importantes para elas na cidade. Ao usar métodos diversificados, dei mais oportunidades às crianças para participar, já que puderam usar diferentes linguagens para se expressarem. Ainda que a fotografia não tenha sentido sozinha, mas somente junto à interpretação e explicação das crianças, os dados visuais gerados ofereceram uma primeira aproximação para entender as condições de vida e as experiências cotidianas das crianças.

A análise desses dados apontou uma primeira questão-chave: as crianças vivem a cidade a partir de quatro espaços-lugares, quais sejam, a família, a escola, os espaços de lazer e os espaços criados por elas próprias ${ }^{2}$. Mais do que isso, esses espaços-lugares só fazem sentido para as crianças porque estão atrelados às suas relações sociais, pautadas pelas amizades, lutas por poder, negociações, trocas inter e intrageracionais. O propósito do presente artigo é explorar uma parte dos resultados dessa investigação, referentes aos processos de socialização na escola a partir do ponto de vista das crianças.

Se por um lado a criança e a infância estiveram pouco presentes nos estudos sociológicos até os anos 1980 (MONTANDON, 1997, 2001; SIROTA, 2001; CORSARO, 1997, 2003, QVORTRUP, 1994), por outro, segundo Mon-

1 Giddens (1991) argumenta que a modernidade separou o espaço do lugar, o que antes era uma categoria única, simultânea, em que as dimensões espaciais da vida social eram caracterizadas pela presença das pessoas. O espaço é separado do lugar ao ampliar as possibilidades de relações - entre outros com quem não há necessariamente contato pessoal. O lugar é familiar, delimitado, específico, concreto, onde nossas identidades estão estreitamente ligadas; também é fixo, onde criamos raízes (HALL,1999). Tuan (1977) explica que, mesmo que espaço e lugar sejam categorias co-dependentes, uma vez que seus significados se misturam, o espaço é mais abstrato que o lugar, isto é, são diferentes. Embora ciente das teorizações que diferenciam o espaço do lugar, eu vou usá-los por vezes como sinônimos, entendendo que isso é o reflexo da sua própria co-dependência. Mais do que isso, a própria cidade é simultaneamente um espaço e um lugar. É nela que as rupturas entre o moderno e o contemporâneo vêm à tona, o que a faz um campo rico de pesquisa.

2 Contudo, uma das crianças participantes do estudo, um menino de quatro anos, não apontou a escola em suas fotografias e conversas. Ele não aparecerá no Quadro I em função do propósito de foco do presente trabalho. 
tandon (1997), a sociologia da educação estudou as crianças tendo como foco as influências das estruturas escolares sobre elas e os adolescentes. Todavia, a criança não era considerada, mas sim a sua trajetória escolar e os processos de socialização na escola. As teorias sociológicas funcionalistas, principalmente elaboradas por Durkheim $(1973,1974)$ e Parsons (1964), tiveram um importante papel ao associar o conceito de socialização a uma concepção de crianças como seres passivos e a infância como um período de passagem, sem importância em si, mas no aguardo pela vida adulta. Populares nos anos 1950 e 1960, essas teorias conceberam a socialização como uma estratégia de treinamento para assegurar a internalização de normas e regras, de forma que as crianças se tornassem integradas à sociedade, o que colaborou para a construção científica da irracionalidade, da natureza e da universalidade da infância.

Parsons (1964, p. 208) chamou de "invasão bárbara" a chegada dos recémnascidos, entendendo isso como uma situação crítica de todas as sociedades. Após o seu nascimento, a criança passaria a ser conformada pelas instituições sociais: a família, a comunidade e a escola. Dessa relação, ela assimilaria a moral e os costumes que conduzem ao convívio social e, aos poucos, incorporaria as regras coletivas aos seus valores individuais, pois, do contrário, ela se tornaria excluída.

Durkheim (1974, p. 5) associou a educação ao processo de socialização, concebendo-a não somente como a ação repetida e sucessiva das gerações adultas sobre as crianças, mas também como um "esforço contínuo para impor às crianças maneiras de ver, de sentir e de agir às quais elas não chegariam espontaneamente". A educação também teria como finalidade promover habilidades físicas, intelectuais e morais, exigidas pela sociedade como um todo, mas igualmente pelos contextos específicos aos quais as crianças pertencem (DURKHEIM, 1973). Essa abordagem defende que a criança passa a ser completa quando já não é mais criança, ao alcançar a maturidade e a completude supostamente particulares à idade adulta.

Não há dúvidas de que o conceito tradicional de socialização apresenta limitações para entender a sociedade contemporânea e a participação das crianças. Seria limitador pensar que o estágio de desenvolvimento físico e emocional ${ }^{3}$ das pessoas determinaria absolutamente a sua participação social. Isso implicaria assumir o desenvolvimento como algo biológico e socialmente limitador e não um processo em constante construção, o que algumas perspectivas da psicolo-

3 De certa forma, a teoria de Jean Piaget corrobora as perspectivas sociológicas tradicionais da socialização. Isso porque prevê comportamentos, ações e modos de pensar próprios para cada etapa da vida, sem considerar a criança como um ser já social. 
gia do desenvolvimento vêm apontando 4 . Pensar a criança em uma sociedade complexa exige o abandono de todas as concepções tradicionais construídas ao longo do século XX, que colocaram-na em uma posição de irracionalidade, incompetência, ignorância e inferioridade em relação ao adulto.

Preocupado em reconstruir o conceito de socialização na perspectiva sociológica, Corsaro (1997) afirma que não se trata unicamente de um problema de adaptação e internalização, mas de um processo de apropriação e reinvenção. A partir de uma visão que considerou a importância do coletivo, de como as crianças negociam, compartilham e criam culturas com os adultos e com seus pares, o autor apresenta o conceito de reprodução interpretativa. Através do termo "reprodução", Corsaro (1997, p. 18) explica que crianças são constrangidas pela estrutura social que impõe a internalização das regras sociais, mas, ao mesmo tempo, estão ativamente contribuindo para a produção e mudança cultural. Enquanto "interpretativa", captura os aspectos inovadores e criativos da participação da criança na sociedade. O conceito de "reprodução interpretativa", logo, compreende que as crianças contribuem para a preservação, assim como para a transformação da sociedade. Também rompendo com o pensamento linear, Thin (2006) não só sugere a relevância de diversas formas de socialização observadas nas condições de existência, nas relações sociais e na história dos grupos e dos indivíduos, mas também a necessidade de avançarmos de uma visão de socialização como o resultado da ação das instituições, para entendê-la como um processo individual e social.

Nesse sentido, é importante considerar o ponto de vista das crianças sobre diferentes processos em suas vidas. Dentre eles, o de socialização na escola, o que exige o esforço de abandono da consideração do ponto de vista adulto. Christensen e James (2003, p. 3) chamam a atenção para a variedade de temas teóricos, práticos, éticos e morais que emergem dos estudos da infância.

O presente artigo apresenta um estudo sobre e com as crianças. A escolha de um número de histórias de vida, capaz de reconstruir a dinâmica históricoestrutural de um grupo social particular, orientou o tipo da amostra da pesquisa. Todavia, face às marcantes diferenças sociais entre as crianças participantes da pesquisa, cabe efetuar uma breve comparação entre os indicadores socioeconômicos dos bairros aos quais elas pertencem. A tabela abaixo mostra que enquanto a renda do responsável pelo domicílio no bairro Bom Jesus é de apenas 4 salários mínimos mensais, no bairro Moinhos de Vento esse valor alcança quase 30 salários mínimos. Vale notar que a desigualdade é ainda maior, uma vez que os domicílios no bairro Bom Jesus são ocupados em média por 3,6 moradores

4 Ver Rossetti-Ferreira, Amorin, Silva e Carvalho (2004) sobre a perspectiva teóricometodológica da Rede de Significações - RedSig. 
contra 2,6 no Moinhos de Vento. Outro fator importante é a grande diferença entre os anos de escolaridade dos moradores do Bom Jesus e dos outros bairros, representando quase a metade se comparado com o Moinhos de Vento e o Bom Fim. Ainda, os bairros Moinhos de Vento e Bom Fim possuem uma baixa participação das crianças na população - apenas cerca de $10 \%$-, enquanto no bairro Bom Jesus um terço da população tem menos de 14 anos de idade. As famílias aqui referidas são representativas das características dos bairros.

TABELA 1 - COMPARAÇÃO DOS INDICADORES SOCIAIS DE BAIRROS SELECIONADOS DE PORTO ALEGRE - 2000

Bom Fim $\begin{gathered}\text { Moinhos de } \\ \text { Vento }\end{gathered}$ Bom Jesus

População residente com até 06 anos de

idade (\%) $\quad 5,1 \quad 4,6 \quad 16,4$

População residente com idade de 7 a 14

$\begin{array}{llll}\operatorname{anos}(\%) & 6,6 & 6,3 & 15,7\end{array}$

Escolaridade média dos responsáveis por

$\begin{array}{llll}\text { domicílios (anos) } \quad 12,7 & 13,2 & 6,5\end{array}$

Taxa de Alfabetização, população 15 anos

$\begin{array}{llll}\text { e mais }(\%) & 99,5 & 99,3 & 92,1\end{array}$

Rendimento médio em Reais dos responsáveis por domicílios $(\mathrm{R} \$)$

2.302

4.479 741

FONTE: Observatório da cidade de Porto Alegre (2007)

A seguir, três temas serão explorados. O primeiro se refere à transição de série e de escola, que implica dificuldades, prazeres e medos para as crianças. O segundo alude à idéia de "ter futuro", assim apresentada pelas crianças mais pobres. Por último, o contexto do recreio é analisado para mostrar a complexidade das relações de amizade entre pares. 


\section{Transições na escola}

Corsaro e Molinari (2005) realizaram uma pesquisa na cidade de Módena, Itália, com o intuito de entender continuidades e descontinuidades nos processos de transição das crianças da Educação Infantil para a primeira série do Ensino Fundamental. O conceito de transição nesse trabalho aparece como os processos coletivos que ocorrem em contextos sociais ou institucionais e que são sempre produzidos e compartilhados com os outros (CORSARO; MOLINARI, 2005). Combinando métodos comparativos com uma etnografia longitudinal, os autores acompanharam as crianças durante o seu último ano na Educação Infantil e o primeiro ano no Ensino Fundamental, quando puderam observar um complexo conjunto de relações nesse rito de passagem.

Embora as oito crianças freqüentassem séries e escolas diferentes, a observação de diferentes processos de transição na escola se tornou evidente. O quadro a seguir apresenta algumas informações sobre as crianças.

\begin{tabular}{|c|c|c|c|c|c|c|}
\hline Ano 2004 & Idade & Gênero & $\begin{array}{l}\text { Série } \\
2004\end{array}$ & $\begin{array}{l}\text { Série } \\
2005\end{array}$ & Bairro & Tipo de escola \\
\hline Jéssica & 9 & $\mathrm{~F}$ & $5^{\mathrm{a}}$ & $6^{\mathrm{a}}$ & Bom Fim & $\begin{array}{c}\text { Pública esta- } \\
\text { dual }\end{array}$ \\
\hline Leonardo & 12 & M & $5^{\mathrm{a}}$ & $5^{\mathrm{a}}$ & Bom Fim & $\begin{array}{c}\text { Pública esta- } \\
\text { dual }\end{array}$ \\
\hline Victória & 9 & $\mathrm{~F}$ & $3^{\mathrm{a}}$ & $4^{a}$ & $\begin{array}{c}\text { Moinhos de } \\
\text { Vento }\end{array}$ & Privada \\
\hline Matheus & 6 & M & $\begin{array}{c}\text { pré- } \\
\text { escola }\end{array}$ & $1^{\mathrm{a}}$ & $\begin{array}{c}\text { Moinhos de } \\
\text { Vento }\end{array}$ & Privada \\
\hline Giuseppe & 7 & M & $2^{\mathrm{a}}$ & $3^{\mathrm{a}}$ & Bom Fim & Privada \\
\hline Adriane & 9 & $\mathrm{~F}$ & $2^{\mathrm{a}}$ & $3^{\mathrm{a}}$ & Bom Jesus & $\begin{array}{c}\text { Pública muni- } \\
\text { cipal }\end{array}$ \\
\hline Élida & 12 & $\mathrm{~F}$ & $6^{a}$ & $7^{\mathrm{a}}$ & Bom Jesus & $\begin{array}{c}\text { Pública muni- } \\
\text { cipal }\end{array}$ \\
\hline Waldemir & 10 & M & $4^{\mathrm{a}}$ & $5^{\mathrm{a}}$ & Bom Jesus & $\begin{array}{c}\text { Pública muni- } \\
\text { cipal }\end{array}$ \\
\hline
\end{tabular}

QUADRO 1 - SÍNTESE DAS INFORMAÇÕES SOBRE OS PARTICIPANTES DO ESTUDO

FONTE: Pesquisa de campo 
Todas as crianças mencionaram experiências atuais ou passadas na escola, principalmente as crianças mais velhas, o que exprime a seguinte condição: maior o tempo de permanência na escola, maior o saber sobre as regras de convívio. Matheus, como uma das crianças mais novas, exemplifica a condição de novato na primeira série do Ensino Fundamental, mostrando nos primeiros meses um exercício permanente para se apropriar das novas normas. O próprio elucida que se confundiu várias vezes, chamando a professora por "tia", mas que ao ser corrigido por ela ou pelos colegas, aprendeu que pode chamá-la por "professora", "sora" ou "profe". Conectar o som da sineta com o horário para se colocar em fila ou ir embora também não é óbvio, o que Matheus aprendeu com a própria experiência de ter sua atenção chamada pela professora por estar atrasado, ou através das dicas da mãe e da irmã mais velha.

As crianças mostram preocupações e experiências sobre eventuais mudanças de escola, que também consiste em um processo de transição. Com base nos depoimentos das amigas, Jéssica opta por permanecer na mesma escola a partir da quinta-série, já que imagina que sua adaptação às regras do Colégio Militar de Porto Alegre seria muito difícil, principalmente ao considerar o uso de uniforme. No entanto, ela entende que o Colégio Militar "é mais forte", isto é, mais competente para preparar os alunos para o futuro vestibular. Também considerando conversas com amigas, Victória compara a sua escola com outras duas da iniciativa privada de Porto Alegre; se na primeira ela somente vê problemas relacionados a prévios acidentes com as crianças, na segunda ela percebe vantagens ao comparar o tempo de recreio com o da sua escola. Giuseppe prevê que estudará em outra escola após a quarta-série, no entanto cogita a possibilidade de ser reprovado, e, logo, de permanecer na escola atual.

Corsaro e Molinari (2005) percebem três ritos de passagem na transição das crianças de uma escola para a outra. O primeiro seria a separação, ou seja, a parte final do último ano na escola; o segundo, a incorporação da cultura da escola nova; e o terceiro seria um processo de passagem entre as duas primeiras. Waldemir, Leonardo e Matheus mudaram de escola e seus relatos sobre esse processo de transição estiveram sempre presentes nas nossas conversas. Waldemir freqüentou a primeira e segunda-séries em uma escola pública municipal, tendo sido transferido para outra escola da mesma rede na terceira-série. Segundo o seu entendimento, esta mudança foi positiva, pois lhe oportunizou mais desafios, já que a escola anterior era considerada por ele como "fraca". Waldemir não expressa qualquer queixa e a conformação às regras da nova escola parece ter sido tranqüila. Leonardo se preparou para duas transições: de série e de escola, mas somente a segunda ocorreu. Mostrando-se desapontado com a reprovação, Leonardo entende que seus professores foram omissos e que não lhe deram chances para ser aprovado para a sexta-série. Apesar de Matheus 
ainda não ter formado um grupo de amigos e sentir-se desconfortável com o comportamento de colegas na nova escola, por "roubar [o seu] lugar na fila", para ele, estar na escola que a irmã mais velha também estuda é motivo de orgulho. Esse sentimento positivo aparece quando ele assume que não pode faltar aulas na nova escola, o que era permitido na escola de Educação Infantil, já que lá "não aprendia nada", e na atual as atividades são "difíceis".

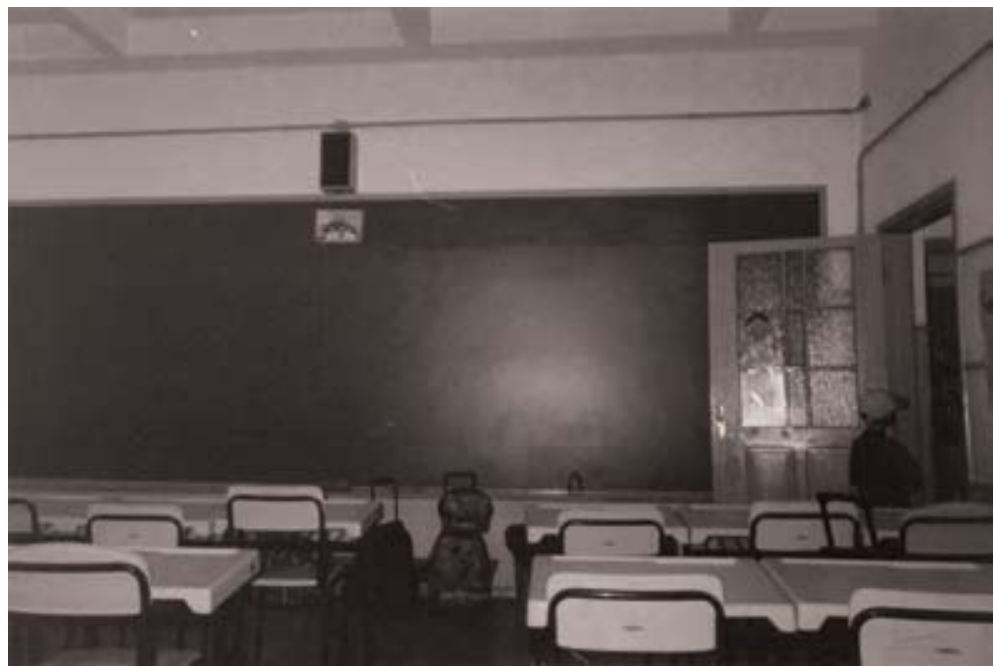

“As coisas que eles [professoras] dão para a gente fazer é difícil” (Matheus, abril 2005)

Negando o conceito de socialização antecipatória ${ }^{5}$, Corsaro e Molinari (2005) preferem chamar as atividades nas quais as crianças vivem mudanças esperadas ou antecipadas nas suas vidas como eventos primários, compreendidos como importantes para a construção dos aspectos temporais, como as transições. Alguns exemplos desses eventos primários podem ser exemplificados pelas visitas feitas pelas crianças às suas futuras escolas.

Daniela (mãe de Victória) e Andréa (mãe de Matheus) expressaram suas visões sobre os processos de transição dos filhos mostrando as suas visões sobre o papel da escola. Daniela reforça que a filha "ama aquele colégio; quero ver

5 De acordo com Merton (1970, p. 347) a socialização antecipatória é a adoção de atitutes e valores de um grupo ao qual não se pertence, tendo uma função dupla de facilitar uma introdução nesse grupo e, ao mesmo tempo, um processo de ajustamento depois que se tornou membro. 
até quando", o que reflete a experiência de um adulto que passou por vários ritos de passagem ao longo da vida e que acredita que, inevitavelmente, a filha ficará aborrecida com a escola nos próximos anos. Ao comparar a escola com a casa, Andréa concorda com as atitudes das professoras quando estas gritam com as crianças. Acreditando que as professoras enfrentam situações difíceis e similares àquelas que ela vivencia em casa, Andréa expressa um sentimento de compaixão pela professora de Matheus, acreditando que ela deve colocar todos "na linha".

\section{O que se aprende na escola?}

A emergência da escola de massas, a nuclearização da família e a constituição de um corpo de saberes da pedagogia e da psicologia formaram um conjunto de prescrições que regram as vidas das crianças na sociedade contemporânea, o que Sarmento (2002) conceituou como administração simbólica da infância e Sgritta (1987) define como institucionalização da infância. A organização sistemática de instituições, regras e instrumentos contribuiu para a institucionalização da infância e para a emergência do ofício de aluno (PERRENOUD, 1995; SARMENTO, 2000, 2002; SACRISTÁN, 2005), exprimindo, assim, as expectativas dos adultos de que a criança se comporte conforme a norma.

O conjunto de comportamentos esperados na escola não é algo que as crianças sabem previamente, mas é aprendido nas relações pessoais e na própria experiência na instituição. De uma forma dialética, Sacristán $(2005$, p. 14) entende que a "infância construiu em parte o aluno, e este construiu parcialmente a infância". Um ofício específico emergiu a partir das expectativas dos adultos sobre as crianças em relação às atividades escolares e aos comportamentos esperados nesse contexto, e isso não é algo que as crianças sabem previamente, mas é aprendido através das relações e da própria experiência na instituição. Este artigo focaliza nas visões das crianças sobre os seus ofícios de aluno.

Se, por um lado, professores, pais e sociedade percebem uma grande crise da escola evidenciada pelo comportamento das crianças e dos adolescentes de desrespeito à autoridade dos adultos, falta de interesse, violência, por outro, ainda há uma expectativa de que a escola seja a responsável pela solução dos problemas sociais. Como pode ser a escola a doença e a cura? Essa é mais uma contradição dos tempos contemporâneos que revela, sobretudo, o quanto a vida das crianças se tornou mais complexa e outros interesses concorrem com o que antes era o reduto quase único de informação e conhecimento. Mais do 
que isso, talvez a diversidade das experiências das crianças venha entrando em choque com aquilo que Thin (2006, p. 217) observa: "se a escola de hoje não é mais aquela em que nasceu a forma escolar, ela conserva lógicas que surgem fundamentalmente dessa lógica escolar".

A escola é entendida como uma possibilidade de mobilidade social para as crianças. Elas a assumem com a prevenção de uma futura condição de "burro". Giuseppe argumentou que as crianças têm a oportunidade de aprender a se organizar na escola, através da delimitação do uso do tempo: a hora do descanso, a hora do lanche, a hora do estudo, o que se diferenciará para cada série. Ao comparar a organização do tempo em sua turma e na de seu irmão, Giuseppe se entende mais responsável, pois, enquanto o irmão eventualmente dorme e tem um intervalo maior, ele tem aulas especializadas, como as de filosofia.

Principalmente entre as famílias pobres, a escola é vista como a esperança de um futuro melhor para o filho, diferente da situação atual dos pais. Coroca (mãe de Élida) diz: "não fomos [ela e o marido] longe", expressando o entendimento de que, embora enfadonha no presente, o valor da escola como criadora de oportunidades na vida poderá ser percebido no futuro. O mesmo ocorre com Vera (mãe de Waldemir) que, tendo em vista um futuro planejado para os filhos, diferente do seu, não mede esforços para que tenham um bom desempenho e se afastem do modelo de aluno (e criança) encontrado no bairro em que vivem (Bom Jesus).

O futuro também está entre as preocupações de Adriane e Élida, que vêem o sucesso como um resultado da aprendizagem na escola. É lá que as crianças aprendem a ser "alguém na vida", de acordo com Élida, que, assim como Adriane, também crê que isso dependerá de outras aprendizagens específicas, tais como: comportar-se, obedecer, não falar "palavrão", não incomodar a professora durante as aulas.

A escola aparece relacionada ao futuro, como se o presente fosse um tempo de infinita espera. Entretanto, como tempo de prazer e de fuga, o recreio é vivido no presente na escola. Tonucci (1997) argumenta que é fundamental às crianças terem direito ao hoje, ao presente. No entanto, também observa que a criança só tem direito ao futuro com base no que será.

A preparação para o futuro pode ser evidenciada na participação das crianças em atividades extra-escolares, com agendas definidas. No período oposto ao da escola, Victória freqüenta aulas de pintura, vôlei, flauta e inglês, consultas semanais com ortodontista e fonoaudióloga. Jéssica tem aulas de inglês e catequese e ainda pensa em realizar um esporte, como natação. Giuseppe freqüenta aulas de natação e de informática à tarde. Jéssica afirma que, embora sua rotina seja cansativa, uma futura boa colocação no mercado de trabalho dependerá desse esforço. 
Corsaro e Molinari (2005) definem a rotina como um grupo de atividades produzidas coletivamente, recorrentes e previsíveis, e a consideram importante porque oportuniza às crianças e aos adultos a garantia de pertencimento a um grupo social. Todavia, Barbosa (2000) alerta sobre a diferença entre cotidiano - o tempo vivido - e a rotina - a organização do cotidiano. A autora (BARBOSA, 2000) assume as antinomias criadas em torno do conceito de rotina e a necessidade de superá-las, com vistas a se pensar em uma ação pedagógica complexa, movida pela tensão e não pela contradição. Obviamente a rotina exige repetição, o que é importante para a organização das crianças e adultos na escola. Contudo, é necessário a tensão e o equilíbrio entre o tédio e o novo, argumento também defendido por Barbosa (2000).

A escola é composta por relações hierárquicas, por vezes desiguais, que exprimem diferenças de tamanho, idade, conhecimento e poder. Leonardo tem uma ampla percepção do reforço de desigualdades nas relações entre adultos (professores) e crianças (alunos) ao mencionar que somente uma das turmas de quintas-série era levada para atividades de recreação no Parque Farroupilha. Ele também menciona práticas punitivas em caso de mau comportamento das crianças, que é registrado em um livro de ocorrências ${ }^{6}$, como também a visita à sala do diretor, a figura de autoridade de maior poder da escola no entendimento das crianças. Adriane afirma gostar da escola porque a "diretora não xinga", enquanto Matheus diz que gosta parcialmente das professoras porque elas "gritam muito".

Todavia, de modo geral, as crianças gostam das suas escolas e os motivos para isso variam, principalmente porque dependem da avaliação que fazem das relações estabelecidas com os adultos e com os seus pares. As disciplinas são gostadas ou abominadas com base nos laços construídos com os professores responsáveis pelo ensino dessas. Élida não gosta de Matemática porque a professora xinga todos os alunos por atos que somente alguns cometeram. Já Leonardo gosta de História e, motivado pelos documentários apresentados nas aulas, quer ser arqueólogo. Waldemir prefere Educação Física e Matemática e fotografou as professoras responsáveis por essas disciplinas. Adriane e Victória mostram interesse pelas aulas de Educação Física, o que de certa forma mostra as suas necessidades de movimento e liberdade no espaço das quadras esportivas, que são consideravelmente maiores que a sala de aula.

6 Ratto $(2002,2006)$ analisa os livros de ocorrência em escolas públicas, mostrando como as relações entre a escola e os pais no campo disciplinar normatizam o comportamento das crianças. 
FOTO 2

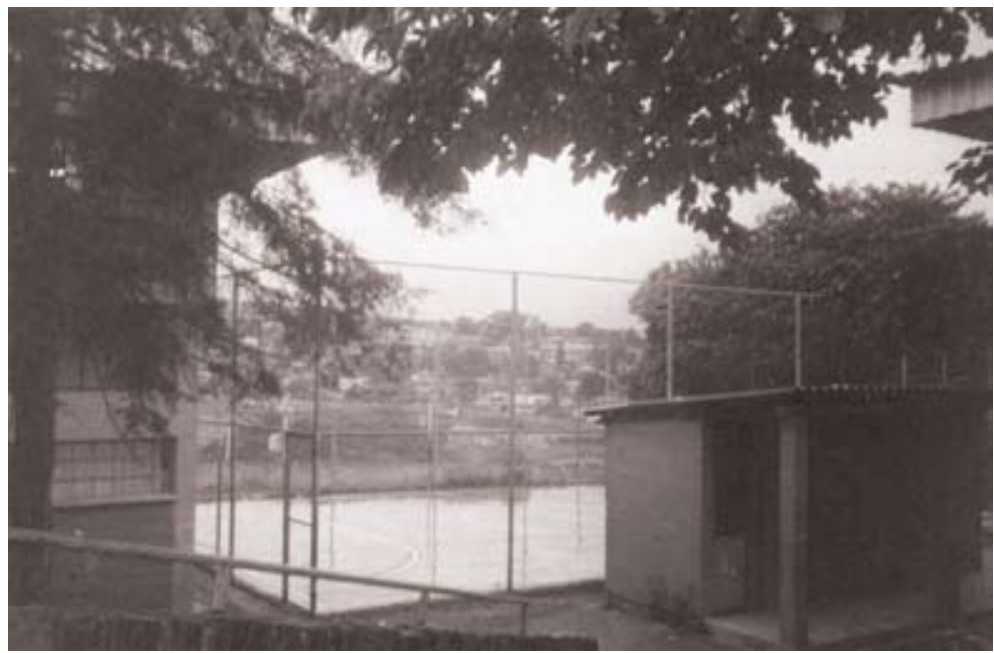

"Quadra de esportes da escola" (Adriane, novembro 2004)

É necessário ainda adicionar que Jéssica, Giuseppe e Victória participam de aulas de Inglês em escolas especializadas, sendo que os últimos ainda realizam aulas de Informática, Esportes e Artes nos horários opostos ao da escola. Todas as crianças, exceto Adriane, Élida e Waldemir têm computador em casa. Leonardo foi quem mais demonstrou conhecimentos sobre o mundo virtual, ainda que sofra as limitações impostas pela família, não tendo acesso a sua própria conta de e-mail, MSN ou Orkut. Ainda que desempenhe um papel de espectador, ele sabe de todos os procedimentos necessários para acessar estes meios e todas as possibilidades decorrentes deles. Embora o computador da casa de Jéssica seja antigo e lento, ela é responsável por procurar no site do programa televisivo "Mais Você", apresentado diariamente na Rede Globo, e imprimir as receitas culinárias que a mãe deseja tentar.

\section{Amizades na escola}

As fases da vida se diferenciam porque estão em relação e não porque estão separadas. Só é possível identificar a infância porque esta é atravessada pelas outras gerações. Em segundo lugar, a presença de uma diversidade de opções 
tecnológicas não se opõe necessariamente à escola, uma vez que oportuniza às crianças experiências diferentes.

As crianças mostram as relações estabelecidas com pares em diferentes contextos, sendo que na escola isso se torna mais evidente pela própria classificação das crianças por faixa etária. A noção de amizade surge com a idéia de atividades compartilhadas em espaços-tempos específicos da escola, como o pátio e o recreio. A importância dos amigos não é só evidenciada na quantidade de fotos onde aparecem, mas em todos os seus depoimentos.

FOTO 3

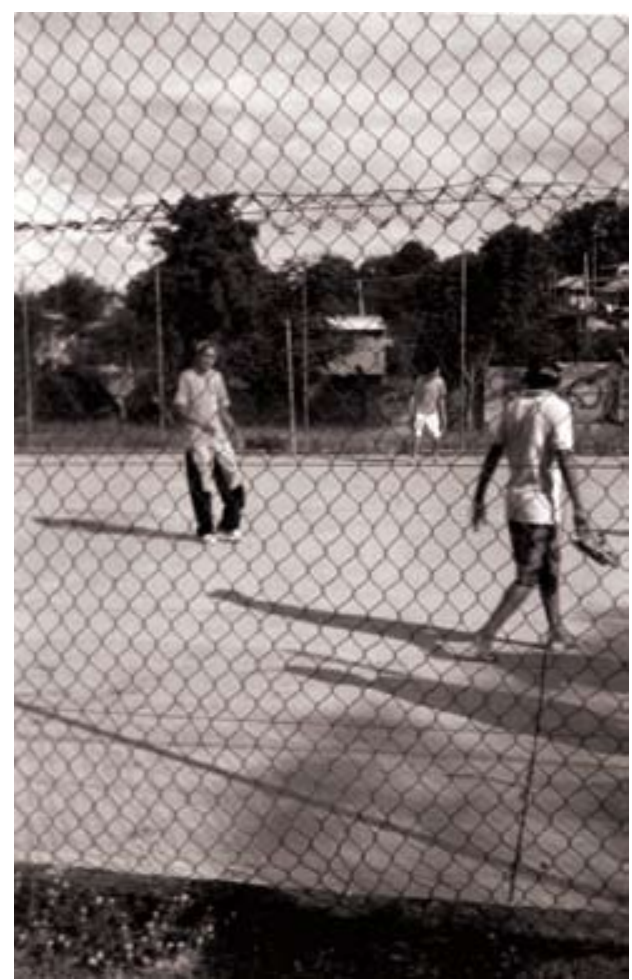

"Amigos no recreio na escola" (Élida, maio 2005)

Jéssica afirma que a escola "faz a gente [os amigos] se encontrar", e igualmente Leonardo quando diz que na escola encontra amigos e assim pode "unir o útil ao agradável: estudo e brinco". 
Definições sobre amizade aparecem de diferentes modos nos relatos das crianças e muito dependem das experiências imediatas, que são por elas usadas como exemplos. Adriane entende que amigos contam segredos e confissões uns aos outros, e nesse caso, ela elege uma das amigas como a melhor porque não só confia nela, mas ela "brinca direitinho" e "se comporta". Tentando diferenciar a intensidade das relações com os seus pares, Leonardo faz questão de caracterizar o que significa ser amigo e ser colega, sendo a última relação mais impessoal e consiste somente na convivência na sala de aula.

O recreio é a categoria espaço-temporal que mais aparece nos relatos das crianças como facilitador do encontro com os amigos. Para todas as crianças o recreio é um dos melhores momentos do dia, senão o melhor, enquanto a sala de aula aparece como o oposto, o lugar e o tempo de ouvir os professores. O espaço é dividido de acordo com os comportamentos esperados das crianças e acabam se transformando em dicotomias, o que Leonardo exemplifica quando afirma que gosta da escola, mas está "enjoado das aulas".

Quando Adriane relata a importância da imagem da santa Nossa Senhora de Fátima no pátio da sua escola, que teria a função de cuidar das crianças, parece que está reconhecendo o fracasso das professoras em fazer aquilo que é esperado delas. A apelação para o divino, externo, sobrenatural a deixa tranqüila, confortada de que alguém está olhando por todos, inclusive pelos adultos. Essa idéia, de certa forma, se conecta às críticas de Leonardo sobre as limitações de somente dois professores para cuidar do recreio que reúne centenas de crianças e adolescentes juntos.

Adriane e Victória chamam a atenção para o espaço físico do recreio em suas escolas, e o desejo de terem acesso aos mesmos brinquedos do pátio da Educação Infantil. Ambas mencionam o espaço lúdico da Educação Infantil, questionando o porquê de não terem as mesmas oportunidades e concluindo que crescer na escola implica na perda de alguns prazeres. É senso comum pensar que somente os adultos e os velhos têm passado, mas as crianças, além de seres biológicos, são igualmente seres históricos, sociais e, demonstram sentimentos de nostalgia. É evidente a saudade de algumas crianças ao falarem sobre o passado na escola, sobre os seus primeiros anos, o que também é exemplificado pela fotografia das professoras do "Jardim da infância", tiradas por Adriane e Élida. Isso mostra que as crianças buscam em alguns adultos e em pares os vínculos emocionais de conforto que estabeleceram primeiro nas suas famílias.

A separação das crianças por gênero aparece somente nas conversas com Adriane, que apóia a existência de quadras de esportes separadas para meninos e meninas, pois em sua opinião "não dá pra misturar; dá briga". A pesquisa de Cruz e Carvalho (2006) sobre as relações das crianças durante o recreio na escola mostrou que os conflitos são modos possíveis de sociabilidade entre me- 
ninos e meninas. Mas do que isso, as autoras (2006, p. 121) conceituam como "sociabilidade do conflito" o duplo movimento de distanciamento, durante os períodos amistosos, e, aproximação, através de ações conflituosas entre meninos e meninas, o que representa a garantia de estar junto.

É também necessário diferenciar o conceito de amizade para os adultos e crianças. Com base em pesquisas nos Estados Unidos e Itália, Corsaro (1997, 2003) concluiu que quando os pais observam grupos de crianças em situações informais, usam diferentes estratégias para encorajar a brincadeira ao invés do conflito entre os seus filhos e outras crianças, fortalecendo assim a associação do conceito de amizade à partilha. No entanto, à medida que as crianças vão formando opiniões diferentes daquelas dos adultos, os conflitos começam a ser entendidos como parte da relação de amizade, o que Jéssica expõe com clareza. Se por um lado, os amigos são aqueles com quem se pode brincar, conversar, ir ao cinema e compartilhar momentos bons da vida, por outro, ela também entende que conflitos e até brigas são inevitáveis e fazem parte do relacionamento. Giuseppe narra diferentes conflitos durante o recreio, quando joga futebol, que o fazem muitas vezes romper com certos amigos. Embora Giuseppe não tenha racionalizado da mesma forma que Jéssica, de que brigas não necessariamente são antagônicas à amizade, seus rompimentos com os amigos não duram mais do que algumas horas. Esse é um outro fator a considerar: rompimentos, conflitos e brigas tomam outras dimensões e significados para as crianças de diferentes idades e adultos, mostrando que em diferentes gerações, essas manifestações resultam de fatores sociais e individuais.

A diferença de idade das crianças que participam do mesmo recreio também é um tema recorrente. Jéssica tem bastante clareza de que crianças pequenas e os "grandões" têm interesses diferentes. Enquanto os pequenos ainda gostam de brincar e correr pelo pátio, os maiores já se organizam em grupos, dançando em rodinha ou apenas conversando. Já Leonardo, mostrando o seu ponto de vista sobre a mesma situação, entende como negativa a aproximação dos maiores com os menores, principalmente porque teme pela segurança daqueles que possam se envolver nas brincadeiras violentas dos "guris maiores e perigosos". Adriane entende que "tamanho não é identidade" ("tamanho não é documento"), pois mantém amigos de diferentes turmas e idades na escola. No entanto, ela associa os "grandes" àqueles alunos reprovados que vandalizam e picham a escola.

Há de considerar também que os ritos de entrada nas brincadeiras não são tão simples como muitas vezes os adultos podem pensar. Dependendo do tempo de aproximação ao grupo e do curso da brincadeira, as crianças protegem seu

7 Ditado popular no Brasil, que significa que tamanho não é uma categoria importante por si só. 
tempo e espaço de outras crianças. Ao ser rejeitado por alguns grupos na escola, Leonardo lidou com esse sentimento escapando para a biblioteca. Já Giuseppe teve sucesso para se inserir em novos grupos adotando a estratégia de passar longos períodos observando e alcançando a bola quando esta saia dos limites da quadra. Uma vez aceito como membro do grupo, a sua entrada se tornou automática nos próximos jogos e brincadeiras.

Especialmente Victória e Matheus se queixam sobre o tempo de duração do recreio, o que nas suas visões é limitado. Victória toma o exemplo de outra escola, que supostamente teria recreio de trinta minutos ou uma hora para mostrar que a sua experiência é muito restrita. Já Matheus, vindo da Educação Infantil, sente tanto que a duração é curta, que pensa que este passa em "um minuto".

\section{Considerações finais}

Se os estudos clássicos da Sociologia apontam a escola como o espaço legítimo de socialização, a sociedade contemporânea apresenta diferentes desafios e possibilidades para as crianças. As novas formas de trabalho, a substituição de uma economia industrial por outra de serviços e os avanços tecnológicos contribuem para a ampliação de opções espaço-temporais para as crianças. Contudo, a escola ainda desempenha um papel fundamental na vida das crianças, como se fosse um dos nós da rede, na qual outras relações serão tecidas e expandidas. As crianças mencionam vantagens e desvantagens em suas experiências na escola e, diante disso, busquei entender as formas mais sutis de expressão desses sentimentos, endereçando o debate para a análise dos processos e não para os resultados. As crianças lidam de formas diferentes com a transição de série e de escola, no entanto é possível generalizar que os mais velhos enfrentam esse rito de passagem com maior familiaridade, já que tiveram mais tempo para se apropriar de regras implícitas da escola. Certas atitudes esperadas não são aprendidas na família ou na escola de Educação Infantil, o que ficou mais evidente na experiência de Matheus. Saber quando e como se organizar na fila e entender que certas ações dependem da autorização dos adultos fazem parte de um aprendizado contínuo e específico da escola.

As crianças mais pobres demonstram a esperança de ter um futuro melhor e diferente das condições que enfrentam enquanto crianças nas suas comunidades. O papel da escola para essas crianças e suas famílias tem estreita relação com esse desejo, explicitado pela necessidade de aprendizagem de conteúdos convencionais (Matemática, Português, Ciências), e de comportamentos sociais. 
As relações de amizade entre pares por vezes são assumidas como opostas às atividades realizadas em sala de aula, principalmente por Leonardo e Élida. No entanto, é interessante notar as definições de amizade que emergem das crianças, nas quais conflitos e brigas seriam fatores combinados e aceitos.

É possível sintetizar que a socialização é um processo relacional envolvendo simultaneamente a internalização e a mudança da sociedade por seus membros. Internalizar significa o aprendizado e a conformação de normas que transformam as pessoas em membros de suas sociedades. Por outro lado, a construção da identidade engloba não apenas a habilidade de se adaptar ao ambiente, mas também de agir e transformá-lo. É o resultado de um jogo de papéis e da síntese de diferentes significações vividas; não haveria uma identidade, porém processos identidários, que são dinâmicos, múltiplos e em constante transformação. Ainda que a escola ainda trabalhe com uma idéia vertical de socialização, as crianças mostram que esse processo é muito mais complexo. Mais do que o entendimento da sua condição social de aluno na escola, as crianças buscam diferentes caminhos para interagir com pares e transformar esse espaço-lugar planejado para elas pelos adultos.

\section{REFERÊNCIAS}

BARBOSA, Maria Carmen Silveira. Por amor \& por força: rotinas na Educação Infantil. Tese (Doutorado) - Campinas: Universidade Estadual de Campinas, 2000.

CHRISTENSEN, Pia; JAMES, Alison. Introduction: researching children and childhood: cultures of communication. In: CHRISTENSEN, P.; JAMES, A. Research with children. Rotledge: Falmer, 2003.

CORSARO, William. The Sociology of Childhood. California: Pine Forge Press, 1997. Press, 2003.

.We're friends, right? Inside kids' cultures. Washington DC: Joseph Henry

CORSARO, William.; MOLINARI, Luisa. Compagni: Understanding children's transition from preschool to elementary school. New York: Teacher College Press, 2005.

CRUZ, Tânia. M.; CARVALHO, Marilia. Pinto. Jogos de gênero: o recreio numa escola de ensino fundamental. Cadernos Pagu, n. 26, p. 113-143, 2006. 
DURKHEIM, Emile. Educação e sociologia. São Paulo: Melhoramentos, 1973. . As regras do método sociológico. São Paulo: Nacional, 1974.

GIDDENS, Anthony. As conseqüencias da modernidade. São Paulo: Editora Unesp, 1991.

HALL, Stuart. A identidade cultural na pós-modernidade. Rio de Janeiro: DP\&A, 1999.

MAYALL, Berry. Conversations with children: working with general issues. In: CHRISTENSEN, Pia; JAMES, Allison (Eds). Research with children: perspectives and practices. London/New York: Routledge/Falmer, 2001. p. 120-135.

MERTON, Robert King. Sociologia: teoria e estrutura. São Paulo: Mestre Jou, 1970.

MONTANDON, Cléopâtre. L'éducation du point de vue des enfants: un peu blessés au fond du coeur. Paris: Editions L'Harmattan, 1997.

. Sociologia da infância: balanço dos trabalhos em Língua Inglesa. Cadernos de Pesquisa, São Paulo, n. 112, p 33-60, 2001.

OBSERVATÓRIO DA CIDADE DE PORTO ALEGRE. Disponível em: $<$ http://www2. portoalegre.rs.gov.br/observatorio $>$. Acesso em: 30/04/2007.

PARSONS, Talcott. Social structure and personality. New York: Free Press of Glencoe, 1964.

PERRENOUD, Philippe. Oficio de aluno e sentido do trabalho escolar. Porto: Porto Editora, 1995.

QVORTRUP, Jens. Childhood matters: social theory, practice and politics. In: QVORTRUP, J.; BARDY, M.; SGRITTA, G; WINTERSBERGER, H. (Ed.). Childhood matters: social theory, practice and politics (Public Policy \& Social Welfare). Aldershot: Avebury, 1994.

RATTO, Ana Lúcia Silva. Cenários criminosos e pecaminosos nos livros de ocorrência de uma escola pública. Revista Brasileira de Educação, Rio de Janeiro, v. 20, p. 95-106. 2002.

. Disciplina, infantilização e resistência dos pais: a lógica disciplinar dos livros de ocorrência. Educação \& Sociedade, Campinas, v. 27, n. 97, p. 1259-1281, dez. 2006. 
ROSSETTI-FERREIRA, M. Clotilde; AMORIM, Katia S.; SILVA, Ana Paula S.; CARVALHO, Ana Maria A. (Orgs.). Rede de significações e o estudo do desenvolvimento humano. Porto Alegre: Artmed, 2004.

SACRISTÁN, José Gimeno. O aluno como invenção. Porto Alegre: Artmed, 2005.

SARMENTO, Manuel Jacinto. O ofício de criança. In: CONGRESSO INTERNACIONAL OS MUNDOS SOCIAIS E CULTURAIS DA INFÂNCIA, 2. Actas... Braga: Universidade do Minho, 2000.

. Administração da infância e da educação: as lógicas (políticas) de acção na era da justificação múltipla. In: CONGRESSO LUSO-BRASILEIRO DE POLÍTICA E ADMINISTRAÇÃO DA EDUCAÇÃO, 2., Braga, Portugal: Instituto de Estudos da Criança, Universidade do Minho, 2002. Texto digitado.

SGRITTA, Giovanni. Childhood: normalization and project. International Journal of Sociology, p. 38-57, Fall 1987.

SIROTA, Régine. Emergência de uma sociologia da infância: evolução do objeto e do olhar. Cadernos de Pesquisa, São Paulo, n. 112, p. 7-31, 2001.

THIN, Daniel. Para uma análise das relações entre famílias populares e escola: confrontação entre lógicas socializadoras. Revista Brasileira de Educação, v. 11, n. 32, p. 211-225, 2006.

TONUCCI, Francesco. La ciudad de los niños: un modo nuevo de pensar la ciudad. Madrid: Fundación Germán Sánchez Ruipérez, 1997.

TUAN, Yi Fu. Space and place: the perspective of experience. Minneapolis: University of Minnessota Press, 1977.

Texto recebido em 04 de junho de 2007. Texto aprovado em 08 de abril de 2008. 